\title{
Multi-taxa spatial conservation planning reveals similar priorities between taxa and improved protected area representation with climate change
}

\author{
Rob Critchlow' (D) . Charles A. Cunningham ${ }^{1,2} \cdot$ Humphrey Q. P. Crick $^{3}$ (D) . \\ Nicholas A. Macgregor ${ }^{3,4}$ D . Michael D. Morecroft ${ }^{3}$. James W. Pearce-Higgins ${ }^{5}$. \\ Tom H. Oliver ${ }^{6}$. Matthew J. Carroll ${ }^{1}$. Colin M. Beale ${ }^{1,2}$ (D)
}

Received: 30 June 2021 / Revised: 11 December 2021 / Accepted: 2 January 2022 /

Published online: 11 January 2022

(c) The Author(s) 2022

\begin{abstract}
Protected area (PA) networks have in the past been constructed to include all major habitats, but have often been developed through consideration of only a few indicator taxa or across restricted areas, and rarely account for global climate change. Systematic conservation planning (SCP) aims to improve the efficiency of biodiversity conservation, particularly when addressing internationally agreed protection targets. We apply SCP in Great Britain (GB) using the widest taxonomic coverage to date (4,447 species), compare spatial prioritisation results across 18 taxa and use projected future (2080) distributions to assess the potential impact of climate change on PA network effectiveness. Priority conservation areas were similar among multiple taxa, despite considerable differences in spatial species richness patterns; thus systematic prioritisations based on indicator taxa for which data are widely available are still useful for conservation planning. We found that increasing the number of protected hectads by $2 \%$ (to reach the $202017 \%$ Aichi target) could have a disproportionate positive effect on species protected, with an increase of up to $17 \%$ for some taxa. The PA network in GB currently under-represents priority species but, if the potential future distributions under climate change are realised, the proportion of species distributions protected by the current PA network may increase, because many PAs are in northern and higher altitude areas. Optimal locations for new PAs are particularly concentrated in southern and upland areas of GB. This application of SCP shows how a small addition to an existing PA network could have disproportionate benefits for species conservation.
\end{abstract}

Keywords Bayesian occupancy modelling $\cdot$ Biodiversity $\cdot$ Habitat restoration $\cdot$ Spatial prioritisation $\cdot$ Species range shifts $\cdot$ Zonation

Communicated by Dirk Sven Schmeller.

This article belongs to the Topical Collection: Biodiversity protection and reserves.

Extended author information available on the last page of the article 


\section{Introduction}

Protected areas are an important tool to mitigate against increasing and unprecedented threats to biodiversity in both terrestrial and marine environments. Terrestrial protected areas cover $15 \%$ of global land area and protect an average of $19 \%$ of all terrestrial species' ranges (Pouzols et al. 2014; Maxwell et al. 2020). Despite the Convention on Biological Diversity's Aichi target to increase land protection to $17 \%$ by 2020 having been missed, the extent of protected areas continues to increase and more ambitious coverage targets are likely to be set in 2022 (CBD 2011; Stokstad 2020). However, meeting these targets by simply increasing the area protected would not by itself guarantee benefits to biodiversity; reflecting this, Aichi target 11 noted the need for "ecologically representative and well connected systems of protected areas and other effective area-based conservation measures". In the past, development of protected area networks has rarely accounted for the spatial configuration of protected areas, leading to considerable inefficiencies (Maiorano et al. 2015) and bias towards areas of low land-use conflict, rather than favouring areas of high biodiversity (Venter et al. 2018). Identifying spatial conservation priorities is a complex process; there are many potential options for creating or expanding protected areas, with high variation in the distribution of species of concern, and finite resources with which to implement the expansion of protected area networks (Kullberg et al. 2015). Often protected area network expansion is informed only by a few well-recorded taxa, resulting in potential problems such as underrepresentation of rare and non-target taxa (Kremen et al. 2008; Delso et al. 2021), or limited species representation, which has a large impact on conservation outcomes (Kujala et al. 2018). Potential shifts in species ranges, resulting from climate change, present an additional challenge to implementing a comprehensive network of protected areas that will benefit biodiversity into the future (Groves et al. 2012; Thomas and Gillingham 2015; Hannah 2010).

Systematic conservation planning (Margules and Pressey 2000) facilitates the identification of areas that could form a comprehensive and representative portfolio of protected sites (Wilson et al. 2009). It typically requires that numerical targets are specified for how much of each important biodiversity element should be conserved, making the planning process transparent (Moilanen and Arponen 2011). We use the term 'systematic conservation planning' synonymously with 'spatial conservation prioritisation/planning', which uses complementarity-based methods to select sites, so protected areas are selected based on how much they would add to the existing network, rather than how much of each feature they contain (Margules and Pressey 2000; Kukkala and Moilanen 2013). Systematic conservation planning can significantly improve the representativeness of the conservation estate and has been widely applied, e.g. South Africa (Smith et al. 2006; Knight et al. 2006) and Australia (Pressey and Bottrill 2008; Barr et al. 2016).

A protected area network should be representative of overall biodiversity, beyond just threatened species. Therefore, including greater taxonomic coverage in spatial conservation planning should result in a better conservation outcome (Kujala et al. 2018; Lehtomäki et al. 2018). Ensuring protected areas are effective in a changing climate is an additional major conservation concern (Gaston et al. 2006; Jones et al. 2016), and conservation prioritisation should be informed by data on projected species climate suitability shifts, particularly if existing protected areas are projected not to retain suitable climatic conditions (Araújo et al. 2011). Determining the potential future effectiveness of existing protected area networks 
requires more evaluation (Gaston et al. 2006), particularly as conservation planning assessments often have limited species or taxonomic coverage (Dockerty et al. 2003; Araujo et al. 2004), in large part because diverse and comprehensive spatially explicit datasets have only recently become available.

Europe is dominated by semi-natural habitats and cultural landscapes due to a history of major land-use change across the continent. It is also a world leading location for driving multinational conservation efforts (Pullin et al. 2009). This includes Natura 2000, the largest coordinated protected area network in the world - consisting of sites designated as Special Protection Areas (SPAs) or Special Areas of Conservation (SACs) (https://ec.europa.eu/ environment/nature/natura2000/). Within Great Britain (GB), SACs and SPAs together with Sites of Special Scientific Interest (SSSIs) form the main protected area designation structure. The overall effectiveness of the GB protected area network has been found wanting in various respects, including the size of many of its sites (most English SSSIs are $<1 \mathrm{~km}^{2}$ ) (Shwartz et al. 2017), in the lack of coherence as a resilient ecological network (Lawton et al. 2010; Cunningham et al. 2021) and in the quality and quantity designated for nature conservation (Starnes et al. 2021). The future effectiveness of the GB protected area network may also be impacted by species' range changes in response to climate change (Mason et al. 2015; Thomas et al. 2012). Despite a number of spatial prioritisations undertaken in the last decade (Delavenne et al. 2012; Dyer et al. 2017; Moilanen et al. 2011), it has not been explicitly utilised for conservation planning policy decisions in GB. Therefore, planning GB protected area networks using a more systematic approach to address current network inefficiencies while also incorporating expected future changes would have clear benefits (Isaac et al. 2018).

However, the amount of data required to ensure biodiversity is fully represented by spatial prioritisation in GB is unknown; prioritisation may be sensitive to the taxonomic groups used or could require only a selection of species or taxa (Kujala et al. 2018). Although SCP has been applied within Britain before (Franco et al. 2009; Moilanen et al. 2011; Thomas et al. 2013; Cunningham et al. 2021), a complementarity-based approach across multiple taxa, while incorporating future expected changes to species distributions, has not been implemented in GB despite the importance of such approaches being shown elsewhere (Kremen et al. 2008; Di Minin and Moilanen 2014; Stralberg et al. 2020; Carroll et al. 2010).

As a first-pass assessment within GB, and working at a $10 \mathrm{~km}$ scale which highlights priority areas to guide fine-scale follow-up, we have three aims. First, to apply systematic conservation planning to recent modelled distributions (1970-1991) of 4447 species in GB to identify priority areas across multiple taxonomic groups, use these to assess the representativeness of the existing designated sites in GB (SSSIs, SPAs and SACs), and to identify where increasing the protected area network to the 2020 Aichi $17 \%$ target would best represent GB biodiversity. Second, we aim to compare how systematic conservation prioritisation differs across an exceptionally diverse set of taxa: plants, invertebrates and vertebrates. Does such a complementarity approach provide better concordance in priority areas between taxa than traditional approaches based on species richness hot-spots (Wilson et al. 2007)? Third, we aim to use projected areas of suitable climate for these 4447 species under a climate change scenario to assess how the current priority areas might change and hence the potential impact of climate change on the representativeness of the current protected area network. 


\section{Methods}

\section{Species data}

Species distribution data were acquired from the Biological Records Centre (BRC) and British Trust for Ornithology (BTO) at $10 \mathrm{~km}$ (hectad) resolution which is consistent with the available data across the widest range of taxonomic groups (Dyer et al. 2017). Data were available for the following groups: ants, spiders, bees, birds, bryophytes, butterflies, ground beetles, centipedes and millipedes, long-horned beetles, ladybirds, craneflies, hoverflies, moths, dragonflies and damselflies, crickets and grasshoppers, plants, soldier beetles and wasps (Table S1). From these species, we classified those listed in Sect. 41 of the Natural Environment and Rural Communities (NERC) Act 2006 as Priority Species (for conservation, usually based on rarity and threat status). Hectads for which climate data were not available were excluded from analyses. Hectads on small islands, isolated from the GB mainland, were also excluded to aid model convergence, giving 2,541 hectads for inclusion in analyses. For all groups other than birds and plants, distribution data were taken only from the period 1970-89; bird data were taken from the Second Breeding Bird Atlas (Gibbons et al. 1993; Gillings et al. 2019), covering the period 1988-91; plant data were taken from the period 1970-86, covering the DC2 date class of the Botanical Society of the British Isles (BSBI) atlas (Preston et al. 2002), and differences in recording effort were accounted for in later modelling. Although more recent data on species distributions are available, all modelled groups were subjects of high recording levels during the period (Pocock et al. 2015) and records may be expected to be closer to equilibrium with their preferred climates during this period as many impacts of anthropogenic climate change were just starting. Similarly, distributions during this period closely match the information available when the bulk of protected areas across GB were designated (Stroud et al. 2001), providing a fairer comparison between spatial conservation planning based selections and actual designation.

If a species was recorded in fewer than five hectads, whether due to low recorder effort or genuinely extremely restricted distribution, it was excluded from the analysis to ensure a minimum amount of data for modelling (Pearce-Higgins et al. 2017). These extreme restricted-range species are expected to be similarly distributed to less rare species and would therefore not be expected to impact the spatial prioritisations (Lennon et al. 2003).

\section{Modelling recent and future distributions}

To model the recent and potential future distribution of these species, we used spatially explicit Bayesian hierarchical models as described by Beale, Brewer, and Lennon (2014). These models simultaneously combine a spatially explicit (conditional autoregressive), generalised additive model, linking distribution to climate with a model that accounts for variation in observer effort. Using occupancy models incorporating taxon-specific estimates of observer effort, we computed the probability of presence independently of the probability of observation. Excluding the rarest species, we analysed 4898 species, for which 4447 models converged and were used to project recent and future distributions (Table S1, full list in Supporting Information). Full details of the models are provided in Pearce-Higgins et al. (2017), with a short summary below. Note that the recent distributions can be taken as a direct measure of occupancy (incorporating all constraints on distribution). This means 
that for well-recorded taxa such as birds, modelling has a negligible impact on estimated recent distribution relative to observed patterns, but for more poorly recorded species modelled distributions are more strongly dependent on estimates of climate suitability in areas of low observer effort. By contrast, future projections are based on climate suitability and an assumption that other geographically structured constraints (e.g. habitat availability, soil type or dispersal barriers) remain unchanged.

For each taxonomic group (Table S1; Supporting Information), we used FRESCALO (Hill et al. 2011) to estimate relative observer effort for each hectad by calculating the proportion of species observed in a hectad compared to expected species richness based on nearby hectads with a similar species composition.

We calculated four bioclimate variables from monthly mean temperature $\left({ }^{\circ} \mathrm{C}\right)$, cloud cover (\%) and total rainfall (mm) from 1961 to 1990 UK Met Office datasets (http://www. metoffice.gov.uk/climatechange/science/monitoring/ukcp09/), aggregating $5 \times 5 \mathrm{~km}$ data to hectad using the mean: (i) mean temperature of the coldest month (MTCO): a measure of winter cold; (ii) growing degree days (GDD5): a measure of the plant growth season; (iii) the coefficient of variation of temperature (cvTemp): a measure of seasonality; (iv) soil moisture (soilWater): a measure of moisture availability that combines rainfall with soil capacity for water and evapotranspiration using a bucket model (Prentice et al. 1993). These four variables are known to correlate with a wide variety of species distributions and describe key bioclimatic variation, balancing ecological relevance and the need to avoid simultaneously fitting several strongly correlated covariates (Beale et al. 2008; Beale et al. 2014).

To project suitable climate space under future climate, we used the Spatially Coherent Projections with 11 regional climate model (RCM) ensemble members from the UK Climate Projections (UKCP09; Murphy et al. 2009) for 2070-2099 for the Intergovernmental Panel on Climate Change's (IPCC) medium emission A1B scenario (equivalent to $4^{\circ} \mathrm{C}$ global warming and intermediate between RCP6 and RCP8.5 (Rogelj et al. 2012)). For each species, we projected future climate space from the 11 climate ensemble members separately. From these 11 projections we calculated the median occupancy probability (i.e. contingent on climate suitability) for each species per hectad for use in further analyses. For both recent and projected distributions we set a threshold of $1 \%$, below which we assumed zero occupancy probability.

\section{Identifying priority conservation areas}

We used the Zonation conservation prioritisation algorithm to identify priority conservation areas (Moilanen et al. 2005). Zonation is particularly suited to the modelled distributions we generated, as it accepts probabilities as input variables. It works by assuming all cells in the landscape are protected, and then seeks to find the cell that can be 'unprotected' with least impact on the biodiversity within the remaining network. This process is repeated until no cells are protected, producing a ranking of the importance of cells across the entire landscape.

Zonation assigns the highest priority to cells with rare species and lowest priority to cells containing only common species. We used the Core-area Zonation (CAZ) model, which is suitable for regions such as GB that have high gradients in species richness, because it assigns the priority of cells according to the rarest species within a cell. Thus cells with 
low overall numbers of species can be identified as priorities if rare species are present (Moilanen et al. 2005). Zonation analysis was performed separately on all taxonomic groups listed in Table S1 for both recent modelled and future projected distributions. It is worth noting that because the prioritisation is based upon the modelled recent distributions and does not include land cover, priority areas identified include both those where species do and will exist, as well as locations where species are currently absent, but are climatically suitable, and therefore where conservation aims could be met best through habitat restoration.

\section{Multi-taxa comparison of priority areas}

To compare the spatial priorities across multiple taxa, we counted the number of times a hectad was selected in the top $10 \%$ of priority hectads for each taxonomic group, repeating this for both recent distributions and projected future distributions. We compared the similarity of richness (summed species probability per hectad) and the priority area patterns between taxa using Pearson's correlations. We also compared the number of occasions when hectads were identified as a priority (i.e., within top 10\%) for all taxa with the frequency with which hectads were selected from 10000 samples of a random draw of $10 \%$ of hectads.

\section{Protected area network (designated sites)}

To determine the efficacy of the existing protected area network for species protection under recent and future climate conditions, we merged the three categories of protected areas (biological SSSIs, SACs, and SPAs) to create a combined 'designated sites network'. All three categories are applicable to the recent species distributions (Stroud et al. 2001). Because many SSSIs are small and geographically widespread, to prevent nearly all GB at $10 \mathrm{~km}$ resolution being considered protected, we considered hectads to be protected only if they had a least $20 \%$ of their area as designated sites. These 'protected' hectads covered $15 \%$ (384 hectads) of GB (Fig. S1), which is equivalent to the combined area coverage of SACs, SPAs and SSSIs. As existing protected areas are extremely unlikely to lose their designation, these 'protected' hectads were then 'locked into' the prioritisation using a Zonation 'mask', ensuring all other hectads are removed first and complementarity to 'protected' hectads is considered. 'Protected' hectads select a slightly more representative distribution of available altitudes than the actual designated sites network (which is heavily biased towards high altitude areas: Fig. S2). Through ranking the conservation prioritisation outputs, we identified hectads where the GB protected area network could be increased to meet the 2020 Aichi 17\% target for either expansion of existing PAs (i.e., in already 'protected' hectads) or location of new PAs (the less-well protected hectads with $<20 \%$ designated sites coverage).

We determined a priori that we would consider species with at least 50 presence hectads (technically, with a summed modelled probability of presence $>50$ ) within the identified network of priority sites as 'adequately protected', and assessed efficacy of the existing designated sites network by calculating the proportion of species meeting this threshold. An alternative approach would be to attempt to protect a certain percentage (e.g. 10\%) of all species ranges, but this would risk inadequately protecting species with small ranges for which we may seek to protect the entire range (cf. the use of absolute areas of occupancy thresholds by IUCN Red List criteria (Butchart et al. 2005)). As the threshold was arbitrary, we repeated the analyses with thresholds for 'adequately protected' of presence in 1,10 , 
75 and 100 hectads, but qualitatively similar results were found; these results are presented only in the Supporting Information and not discussed further. Four hundred (8.7\%) species were recorded in less than 50 hectads of the protected area network, and even more species are projected to fall short of this threshold in the future $(\mathrm{N}=767,16.7 \%)$. Therefore, to estimate relative representation of the reserve network for both time periods, we compared the proportion of species adequately protected within the network against the maximum proportion that could be protected in the same number of hectads (i.e., a hypothetical optimised de novo reserve selection). Finally, to assess whether optimisation of site selection is required, or whether a simple random selection of hectads is adequate, we compared the modelled proportion of species adequately protected under the recent and future conditions within the existing designated site network with the results of 10000 randomly selected reserve networks containing the same number of hectads.

\section{Results}

Despite differences between species richness patterns of some taxonomic groups, such as bryophytes, birds and odonata (Fig. 1), priority areas for conservation identified by Zonation tended to coincide across taxa (Fig. S4, Fig. 1), even for bryophytes where richness patterns were negatively correlated with all other taxa (Fig. S5). There would be marginal returns in identifying priority areas among taxa after including approximately 700 species (Fig. S6). Almost half (44.0\%) of hectads (1119) were not classified as priority areas for any group, $19.8 \%$ (502) of hectads were classed as a priority for at least one group, while $5.2 \%$ (131 hectads) are priorities for more than half of the taxonomic groups. The top $10 \%$ of priority areas among the 18 taxa for recent distributions consistently occurred in the same geographic locations: northern and upland areas, and regions within Southern England (Fig. 2a). Spatial priorities between taxa overlapped more than expected by chance; for a network of protected areas conserving six or more taxa, more of the hectads selected by Zonation are priorities than would be selected through a random selection (Fig. 3). Conservation priority patterns for individual taxonomic groups are provided in the Supporting Information (Figs. S3-S4).

Future priority areas had similar spatial configurations to the recent modelled distributions (Fig. 2). The simulations indicate increases in potential conservation priority of upland and northern areas such as the southern Pennines and northern Scotland (Fig. 2b). Some

Fig. 1 Priority conservation areas among taxa identified using Zonation (using CAZ which reflects the importance of the area for unique rare species). In the priority maps (green), a rank of 1 represents the highest priority hectad. Patterns of priority areas are generally more similar among taxa than patterns of species richness (inset maps in red)
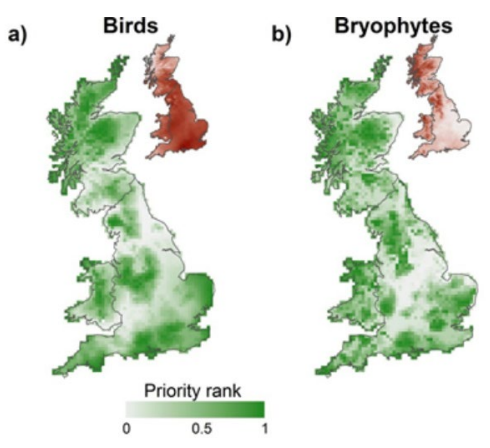

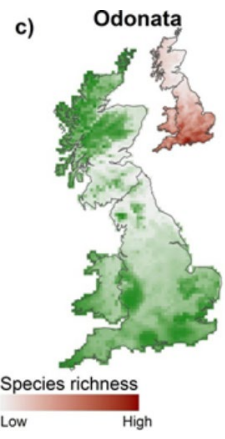




\section{a) Recent scenario}

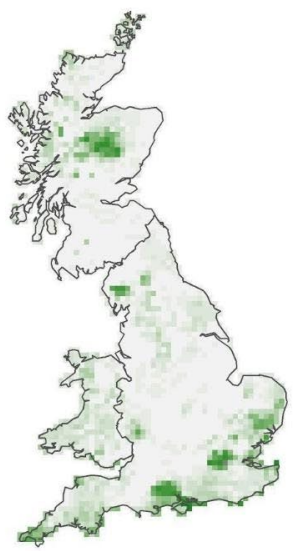

Priority rank frequency

$\begin{array}{lllll}0 & 4 & 8 & 12 & 16\end{array}$

c) Recent - future change

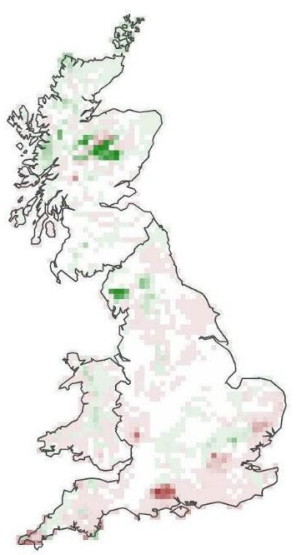

Recent-future change

$\begin{array}{cc}\text { Priority } & \text { Never Priority } \\ \text { decrease } & \text { priority increase }\end{array}$

b) $4^{\circ} \mathrm{C}$ change scenario

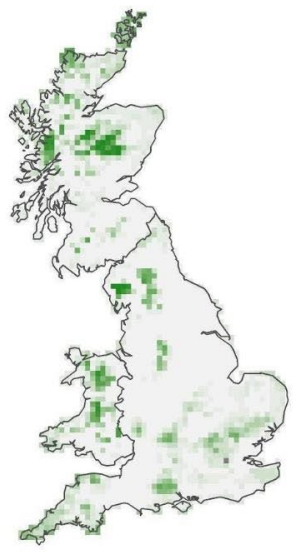

Priority rank frequency

$\begin{array}{llll}0 & 5 & 10 & 15\end{array}$

d) High priority cells

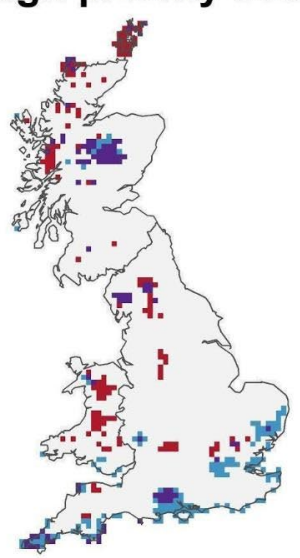

High priority cells

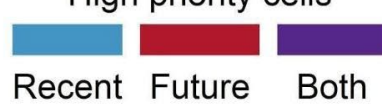

Fig. 2 Occurrence frequency of the top 10\% of priority areas across all 18 taxonomic groups for (a) modelled recent climatic suitability and (b) future climatic suitability. Priority rank is equivalent to the number of taxa that have a particular hectad as a priority. Changes between recent and potential future priority (i.e. rank) are shown in (c); the colour intensity represents the importance in both recent and future conditions, with high intensity indicating relatively high spatial priority (rank) in both recent and future climatic conditions. The top $10 \%$ of both recent and future priority areas are shown in (d) 


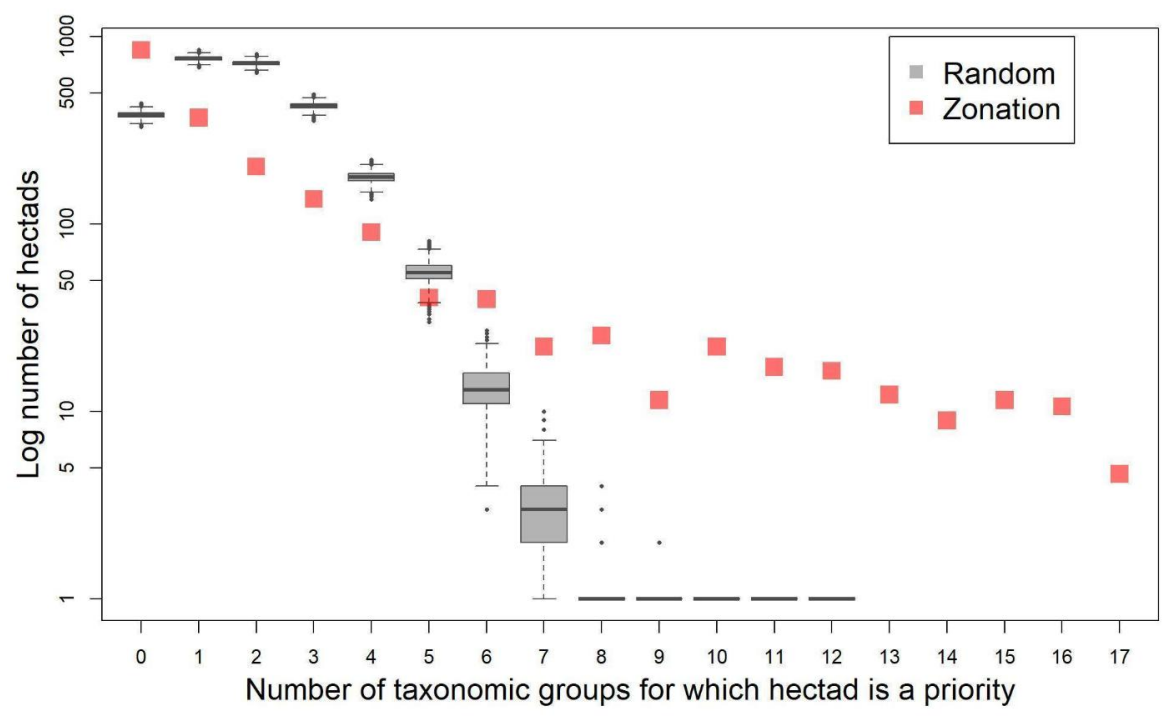

Fig. 3 The frequency of hectads that are independently identified as conservation priorities for increasing numbers of taxonomic groups. Conservation priority hectads fall in the top $10 \%$ of Zonation priorities. Red squares show the actual results of the zonation analysis, such as c. 400 hectads are priorities for one (and only one) taxonomic group and 5 hectads are priorities for 17 groups. Boxplots show the equivalent results for 10,000 random selections of $10 \%$ of hectads. We infer that more hectads are priorities for more than 6 taxa than expected by chance

southern areas retain high priority (conditional on suitable habitat being present) under projected future climate conditions although absolute priority level decreases (Fig. 2c). There were also increases in the priority of currently rather low priority areas, such as upland regions of Wales and in the Pennines. Compared to the recent modelled distributions, under a future climate scenario fewer hectads, $15.2 \%$ (387), were identified as a conservation priority for at least one taxonomic group. Conservation priority maps for individual taxonomic groups using the future climate space scenarios are provided in the Supporting Information (Figs. S7-S10).

For the recent modelled distributions, $69 \%$ of all species are adequately protected (i.e. are present in $>50$ protected hectads) by the existing designated sites network (Table 1). There are major differences among taxa-for example more than $80 \%$ of craneflies, hoverflies and soldier beetles are adequately protected compared to only $52 \%$ of orthopteran species (Table 1; column 2). Taxa with a high proportion of northern or upland species, such as bryophytes, craneflies, and birds, had a greater proportion of recent modelled distributions protected in the current protected area network than in a randomly selected reserve network (Table 2; column 2). 53\% of analysed Priority species are adequately protected. If a similar land area ( $15 \%$ of hectads) to that currently protected were to be selected afresh, without any reference to current designated sites, $73 \%$ of all species and $57 \%$ of priority species could be adequately protected (Table 1; column 1), assuming the selected areas contained suitable habitat for protection or could be prioritised for habitat creation. Optimal allocation increases the relative protection for all groups, but could provide substantially increased protection for some (e.g., orthoptera would increase to $90 \%$ adequately protected). The 
existing designated sites network also performs better under future climatic conditions; there was an increase in the proportion of species adequately protected compared to recent modelled distributions (Table 1; columns 9 and 10) and there was a significantly lower proportion protected in the future compared to a random allocation (Table 2-columns 5 and 6).

By ranking the zonation outputs, we can identify the priority hectads where an increase in GB protected area to $17 \%$ could be located. Increasing the proportion of hectads protected from 15 to $17 \%$ using an optimal allocation based on all species would increase the proportion of species modelled to be adequately protected by $4 \%$; among individual taxonomic groups the increase in proportion of species protected varied between $0 \%$ and $17 \%$ (Table 1). For example, the proportion of bee and long-horned beetle distributions adequately protected would both increase by $16 \%$, and proportion priority species protected would increase by 3\% (Table 1-column 4). If protected areas were optimally increased to $17 \%$ coverage, a greater proportion of species protection across all taxa is expected in comparison to a random hectad selection of $17 \%$ (Table 2).

The majority of hectads recommended for expansion of protected areas (i.e., in hectads that already have protected areas) are in northern areas such as the Lake District and Scottish Highlands (Fig. 4b). In contrast, areas recommended for new protected areas are mostly located in southern England and western Scotland (Fig. 4c), with 67.6\% of hectads also neighbouring hectads with existing protected areas (Fig. S11). Under the future climate scenario, an increase in the percentage of hectads protected to $17 \%$ would increase the absolute proportion of all species adequately protected by $2 \%$, with long-horned beetles benefiting the most from an increase in protected area with an absolute increase of $10 \%$ (Table 1 - column 8).

\section{Discussion}

Using the widest taxonomic coverage in GB to date to inform systematic spatial conservation planning (4447 species across 18 taxa), we identified a suite of priority areas for focusing habitat protection or restoration, based upon their climatic suitability. Although species richness patterns differ, similar areas were identified as conservation priorities across the taxonomic groups. The location of priority areas remained relatively consistent between recent and future climate scenarios (Fig. 2a and b), but the relative importance of these areas changed, with northern and upland areas potentially becoming more important, as widely predicted under climate change scenarios (Mason et al. 2015; Shwartz et al. 2017).

Despite considerable spatial variation in species richness patterns across taxonomic groups, the existing protected area network adequately protected the majority of GB species $(69 \%)$. A reasonable conclusion would be that focusing protection on a broad geographic range and diversity of habitats based on vegetation, indicator taxa and rare species has been beneficial for the conservation of a much wider group of species in GB. The similarity of conservation priority areas among taxa is perhaps because biodiversity has become concentrated in the remaining semi-natural habitat, driven by historical land-use patterns. For example, 47\% of semi-natural grasslands in England were lost between 1960 and 2013 (Ridding et al. 2015), and 46\% of ancient semi-natural broadleaved woodland were lost between 1930 and the 1980s (Ratcliffe 1984). This pattern of conservation priority areas is likely to be found elsewhere in Europe where protected area networks are similar and 


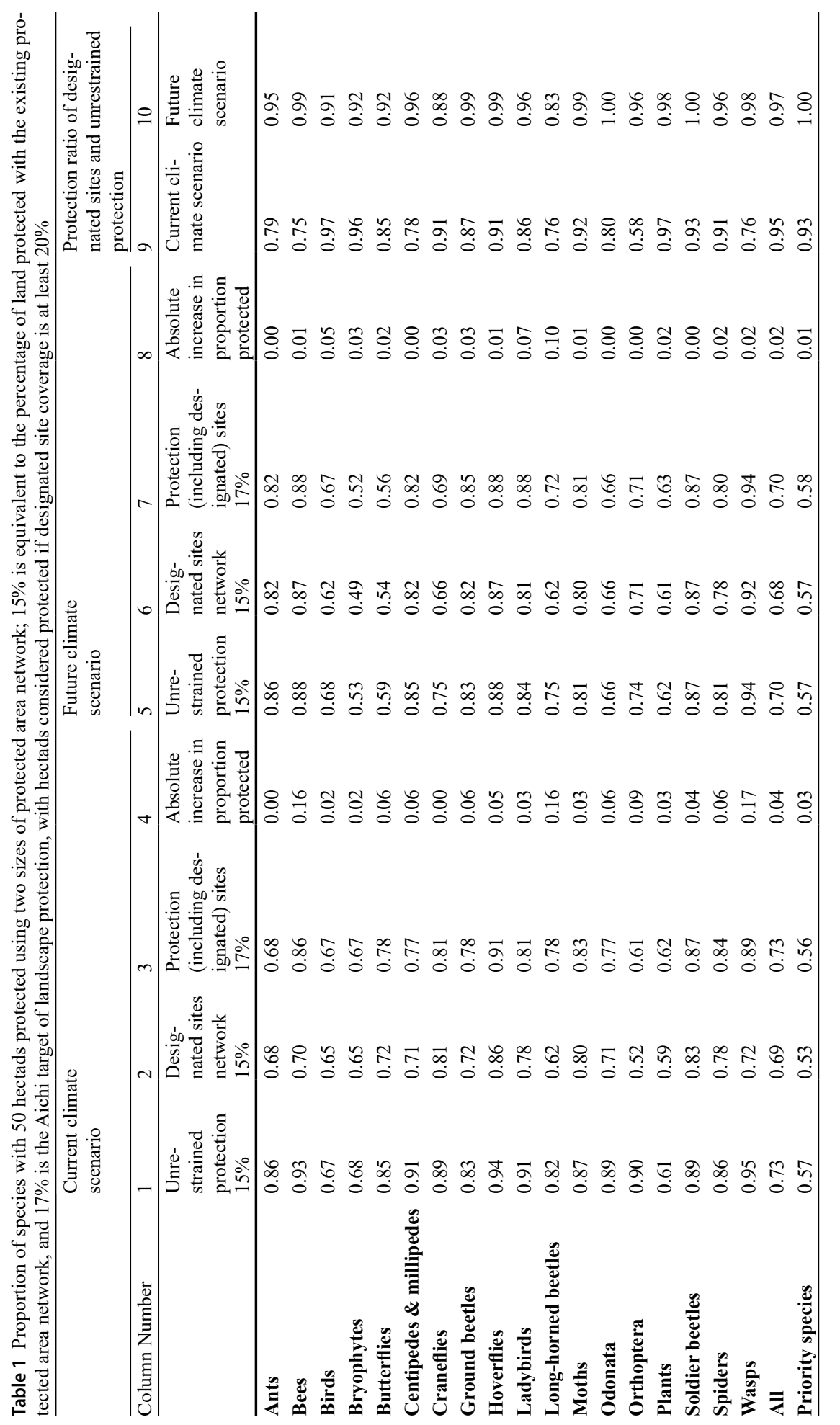




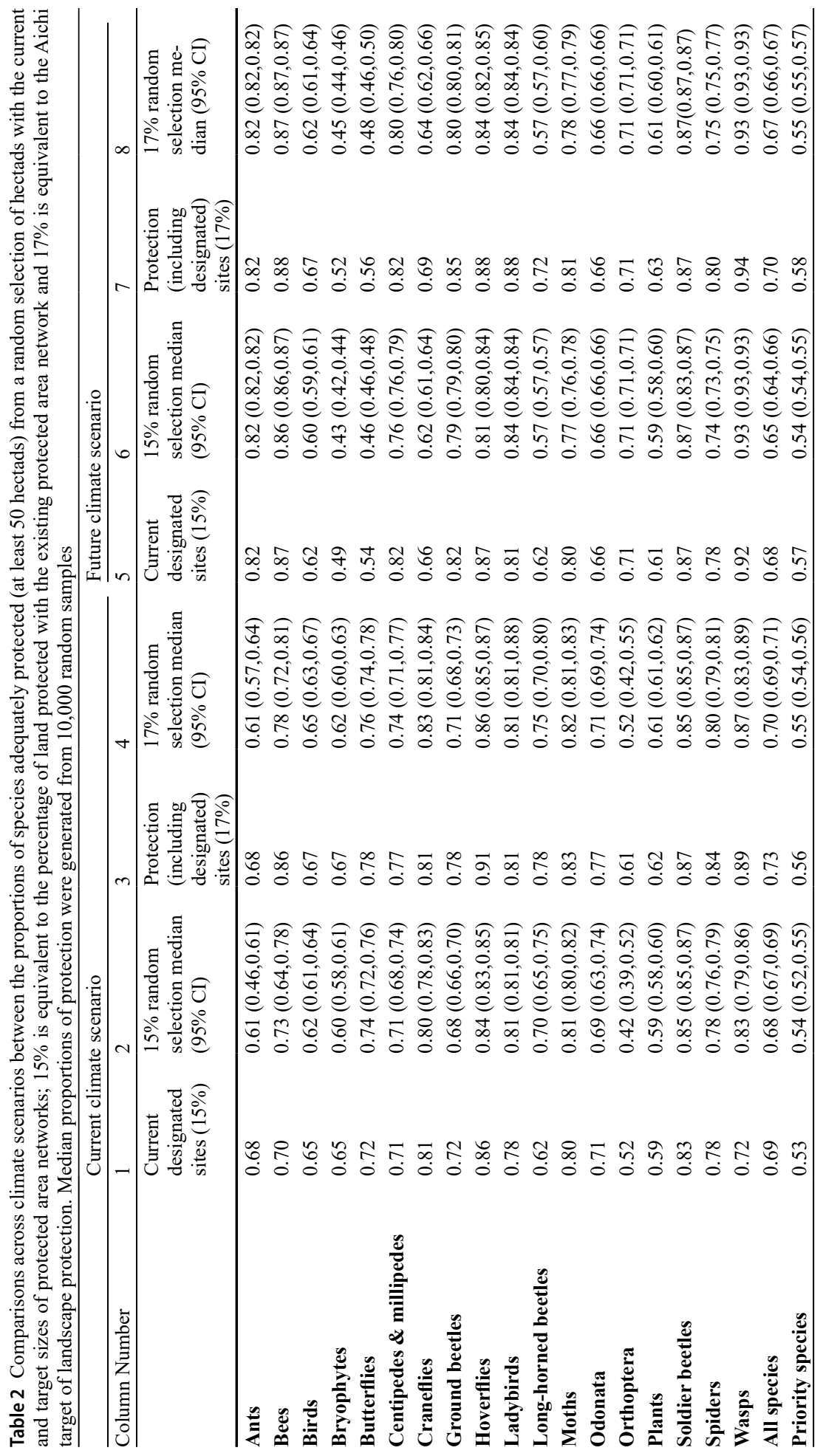


a) Coverage of designated sites

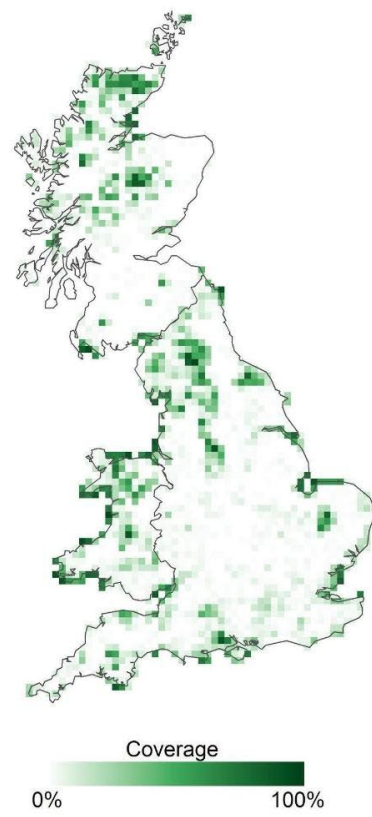

b)Cells for expansion of designated sites

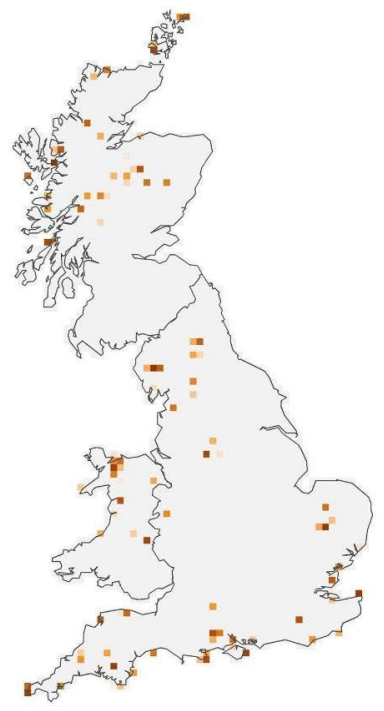

\section{c) Cells for new designated sites}

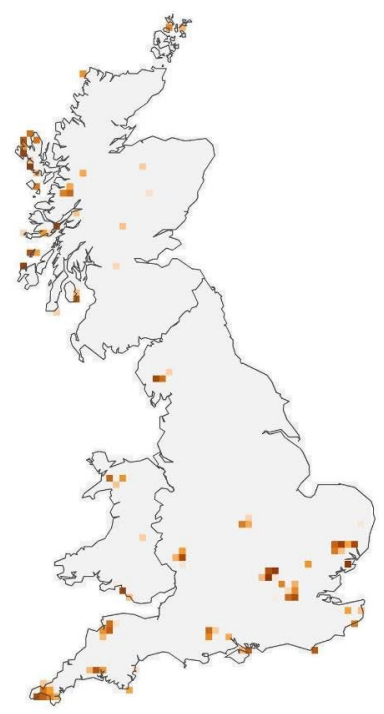

Conservation priority

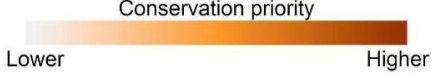

Fig. 4 Coverage of designated sites per hectad (a), recommended hectads to expand existing designated sites (b) and recommended hectads to create new designated sites (c) identified by Zonation to highlight priority conservation areas

historical land-use change has been the major influence on the distribution of extant seminatural habitats. Spatial priorities for protected species overlapped strongly with priorities for individual taxonomic groups, suggesting that together, threatened (priority) species may be a suitable surrogate group for prioritising conservation areas, presumably because when threatened species are present within another assemblage their often small ranges have a large influence on the overall selection algorithm. Although spatial priorities of specific taxonomic groups with more species were more similar to priorities of full assemblage of species, gains in similarity became smaller as species were added. This suggests the benefits of including additional species declines as the number of species increases (Fig. S6). The spatial overlap of priority species also has relevance to the broader geographic scale, with at least $16 \%$ of GB species also being listed on European Red Lists of Species (Table S6). The distribution of GB priority areas is also similar to the pattern of priority areas identified using finer resolution $\left(2 \mathrm{~km}^{2}\right)$ data (Thomas et al. 2013), suggesting that at a broad, countrylevel scale, biodiversity data at hectad level may be sufficient for identifying priority conservation areas, particularly as priority hectads are similar irrespective of the taxonomic group used to determine the spatial prioritisation.

If our projections of future distributions are realised, overall, and for most individual taxonomic groups, a higher proportion of species will be adequately protected in the future. This future increase in adequate protection reflects the ongoing and expected climate-driven 
range shifts towards higher latitudes and elevations (Mason et al. 2015) and the larger area of designated sites in northern and upland areas, mirroring historical land-use patterns, with more arable agriculture in lowland southern areas (Shwartz et al. 2017). This over-representation of upland areas in the British protected area network is similar to the global pattern of designated sites (Joppa and Pfaff 2009), and suggests that similar results would be found elsewhere. Combined with evidence that species currently distributed in northern and upland areas are vulnerable to climate change (Pearce-Higgins et al. 2017), this emphasises the importance of these areas for conserving biodiversity in GB.

Our results therefore suggest that the current designated sites network in GB is geographically well positioned for species conservation in the future, extending the results of previous analyses of the SPA network for birds (Johnston et al. 2013). Hence maintaining existing designated sites, particularly within the identified priority conservation hectads, remains an important component of effective conservation in a changing climate, although the management may need to change as the species for which these areas are likely to be important in the future may have different habitat requirements. It should also be remembered that our analysis did not take explicit account of whether other factors, such as geology and land-use, affect the potential suitability of these sites for colonisation by species from more southerly areas and lower altitudes, but at a national scale, semi-natural habitats are dominant in both recent and future high priority hectads (Fig. S11). The future projections also assume that geographically structured constraints (e.g., habitat availability, soil type or dispersal barriers) remain unchanged. It is therefore possible that areas of forecast high importance may be located where none of the species of interest actually occur. In such cases, priority sites should be taken to indicate priority locations for habitat creation to facilitate colonisation.

As well as the importance of upland areas, our results also highlight the importance of protecting climatically suitable areas for both recent and future distributions of species occurring in the south of GB (high intensity colours; Fig. 2c, d). Furthermore, our analysis only considered species extant in GB; those moving northwards from continental Europe were not included in the modelling process meaning the overall importance of protected areas in southern GB may be underestimated (Fig. 2c, Fig. S8). Southern GB currently has less protection than the north in smaller, more vulnerable protected areas (Cunningham et al. 2021) and conservation action in priority areas here should focus on improving resilience and adaptation to climate change through landscape-scale habitat restoration and connectivity networks (Oliver et al. 2017; Isaac et al. 2018). Although designated sites in Southern GB may lose species they are currently designed to protect, these are likely to be replaced by new colonists (Johnston et al. 2013), which often colonise protected areas before other sites (Gillingham et al. 2015; Hiley et al. 2013).

We found that increasing land protection by $2 \%$, to $17 \%$ of hectads, would increase the proportion of all species considered adequately protected by $4 \%$. The exact percentage increases across taxa are dependent on the arbitrary 50 hectad threshold we choose; however, whatever the threshold, there is always a disproportionate increase in the proportion of species that meet it, if new reserves are selected using optimisation. The same pattern is true for threatened species, and although the increase in protection for this group by $3 \%$ is lower than for most individual taxa, this is because threatened species have small geographic ranges, and many never reach the threshold of adequate protection (50 hectads). Furthermore, even for taxa for which the current network performs worse than a random selection of protected areas (e.g., long-horned beetles, soldier beetles and wasps; Table 2), 
spatial prioritisation and a $2 \%$ increase in land protection improves the representation of currently under-represented taxa.

Our national approach has identified priority landscapes which can be further interrogated to take into account factors that aid species persistence, including climatic refugia (Suggitt et al. 2018). Conservation of priority hectads does not necessitate strict protection across the whole area, but instead provides a guide for focusing conservation action. To improve integration with land-management units (Pierce et al. 2005) and the efficiency of conservation actions, finer scale assessments informed by our analysis, within hectads, should also be implemented (Butchart et al. 2012; Gilby et al. 2021). For example, each hectad could be assessed to identify whether the key species driving the prioritisation are already adequately protected within small reserves not identified in this analysis because of the protection threshold; many of the priority hectads will already contain protected areas that are doing an adequate job of protecting priority species. The spatial conservation prioritisations identified strong integration of priority hectads, particularly for future distributions, with the existing protected areas (Fig. S12). Maintaining this connectivity between protected areas and future species distributions is also fundamental for spatial coherence and conservation success (Saura et al. 2014).

Using a multi-species and multi-taxa approach, we found that priority areas for many taxa show strong geographic overlap, irrespective of the spatial richness patterns. This indicates that using a subset of species, such as priority species, might provide a reasonable proxy to inform spatial conservation planning in GB. We also found the current protected area network is likely to increase in value for current native species as climate drives a redistribution of species across GB towards more protected northern and upland landscapes. At this spatial scale, spatial conservation planning tools, such as Zonation, can be used to aid the design, rather than decide the exact structure, of a protected area network. Ultimately, any additional protected areas will also be influenced by socio-economic factors (Bode et al. 2008) as well as considerations of quality and connectivity between existing and future protected areas (Hodgson et al. 2009; Moilanen et al. 2005). In addition to using spatial conservation planning to improve existing area-based conservation, we recommend the inclusion of predicted species distributions from multiple taxa to provide policy makers with an assessment of the future effectiveness of existing protected area networks under changing climatic conditions.

Supplementary Information The online version contains supplementary material available at https:/doi. org/10.1007/s10531-022-02357-1.

Acknowledgements The modelled species distributions were derived from raw data provided by the relevant national recording schemes and societies as part of the work by Pearce-Higgins et al. (2017). Other than Specific thanks go to Chris Preston and Oli Pescott (British Bryological Society), Mark Telfer (Ground Beetle Recording Scheme), Tony Barber (British Myriapod \& Isopod Group (Centipede Recording Scheme), John Kramer and Alan Stubbs (Cranefly Recording Scheme), Stuart Ball, Roger Morris, Joan Childs and Ellie Rotheray (Hoverfly Recording Scheme), Keith Alexander (Soldier Beetles, Jewel Beetles and Glow-worms Recording Scheme), Kevin Walker (Botanical Society of Britain and Ireland (BSBI), Richard Fox (Butterfly conservation), Peter G. Sutton (Orthoptera and Allied Insects Recording Scheme of Britain and Ireland), Tom August (NERC Centre for Ecology \& Hydrology) and Peter Harvey (Spider Recording Scheme). We also gratefully acknowledge the efforts made by the many volunteer recorders who have provided data to these schemes, such a project would not be possible without their contributions. This project was funded by Natural England and CEC was supported by the Natural Environment Research Council (grant NE/R012164/1). 
Authors' contributions Design-RC, HQPC, NAM, MDM, JWPH, CMB. Data and Analysis-RC, CMB, MJC. Writing_All authors.

Funding This project was funded by Natural England and CEC was supported by the Natural Environment Research Council (grant NE/R012164/1).Availability of data and material Raw data is available from the relevant national recording schemes and societies as part of the work by Pearce-Higgins et al. (2017).

Code Availability R code available from corresponding author.

\section{Declarations}

Conflicts of interest/Competing interests We declare no conflict of interests.

Additional declarations for articles in life science journals that report the results of studies involving humans and/or animals Not applicable.

Ethics approval Not applicable.

Consent to participate Not applicable.

Consent for publication Not applicable.

Open Access This article is licensed under a Creative Commons Attribution 4.0 International License, which permits use, sharing, adaptation, distribution and reproduction in any medium or format, as long as you give appropriate credit to the original author(s) and the source, provide a link to the Creative Commons licence, and indicate if changes were made. The images or other third party material in this article are included in the article's Creative Commons licence, unless indicated otherwise in a credit line to the material. If material is not included in the article's Creative Commons licence and your intended use is not permitted by statutory regulation or exceeds the permitted use, you will need to obtain permission directly from the copyright holder. To view a copy of this licence, visit http://creativecommons.org/licenses/by/4.0/.

\section{References}

Araújo MB, Alagador D, Cabeza M, Nogués-Bravo D, Thuiller W (2011) "Climate change threatens european conservation areas". Ecol Lett 14(5):484-492

Araujo MB, Cabeza M, Thuiller W, Hannah L, Williams PH (2004) "Would Climate Change Drive Species out of Reserves? An Assessment of Existing Reserve-Selection Methods". Glob Change Biol 10(9):1618-1626

Barr LM, Watson JEM, Possingham HP, Iwamura T, Fuller RA (2016) "Progress in Improving the Protection of Species and Habitats in Australia". Biol Conserv 200:184-191

Beale CM, Brewer MJ, Lennon JJ (2014) “A New Statistical Framework for the Quantification of Covariate Associations with Species Distributions.” Edited by Darren Kriticos. Methods Ecol Evol 5(5):421-432

Beale CM, Lennon JJ, Gimona A (2008) "Opening the Climate Envelope Reveals No Macroscale Associations with Climate in European Birds". Proc Natl Acad Sci USA 105(39):14908-14912

Bode M, Wilson KA, Brooks TM, Turner WR, Mittermeier RA, McBride MF, Underwood EC, Possingham HP (2008) "Cost-Effective Global Conservation Spending Is Robust to Taxonomic Group”. Proc Natl Acad Sci 105(17):6498-6501

Butchart SHM, Jörn PWS, Mike IE, Suhel Q, Salvatore A, Julius A, Mark B et al (2012) "Protecting Important Sites for Biodiversity Contributes to Meeting Global Conservation Targets". PLoS One 7(3):e32529

Butchart SHM, Stattersfield AJ, Baillie J, Bennun LA, Stuart SN, Akçakaya HR, Hilton-Taylor C, Mace GM (2005) "Using Red List Indices to Measure Progress towards the 2010 Target and beyond". Philos Trans R Soc Lond B Biol Sci 360(1454):255-268

Carroll C, Dunk JR, Moilanen A (2010) "Optimizing Resiliency of Reserve Networks to Climate Change: Multispecies Conservation Planning in the Pacific Northwest, USA”. Glob Change Biol 16(3):891-904

CBD (2011) "Conference of the Parties Decision X/2: Strategic Plan for Biodiversity 2011-2020 
Cunningham CA, Chris D, Thomas MD, Morecroft, Humphrey QP, Crick, Beale CM (2021) “The Effectiveness of the Protected Area Network of Great Britain”. Biol Conserv 257(May):109146

Delavenne J, Metcalfe K, Smith RJ, Vaz S, Martin CS, Dupuis L, Coppin F, Carpentier A (2012) "Systematic Conservation Planning in the Eastern English Channel: Comparing the Marxan and Zonation DecisionSupport Tools". ICES J Mar Sci 69(1):75-83

Delso A, Fajardo J, Muñoz J (2021) “Protected area networks do not represent unseen biodiversity”. Sci Rep 11(1): 12275

Di Minin E, Moilanen A (2014) "Improving the Surrogacy Effectiveness of Charismatic Megafauna with Well-Surveyed Taxonomic Groups and Habitat Types". Edited by Jeroen Minderman. J Appl Ecol 51(2):281-288

Dockerty T, Lovett A, Watkinson A (2003) "Climate Change and Nature Reserves: Examining the Potential Impacts, with Examples from Great Britain”. Glob Environ Change: Hum Policy Dimens 13(2):125-135

Dyer RJ, Gillings S, Pywell RF, Fox R, Roy DB, Oliver TH (2017) “Developing a Biodiversity-Based Indicator for Large-Scale Environmental Assessment: A Case Study of Proposed Shale Gas Extraction Sites in Britain". Edited by Ben Collen. J Appl Ecol 54(3):872-882

Faleiro FV, Ricardo B, Machado, Loyola RD (2013) "Defining Spatial Conservation Priorities in the Face of Land-Use and Climate Change". Biol Conserv 158(February):248-257

Franco AMA, Anderson BJ, Roy DB, Gillings S, Fox R, Moilanen A, Thomas CD (2009) "Surrogacy and Persistence in Reserve Selection: Landscape Prioritization for Multiple Taxa in Britain". J Appl Ecol 46(1):82-91

Gaston KJ, Charman K, Jackson SF, Armsworth PR, Bonn A, Briers RA, Callaghan CSQ et al (2006) "The Ecological Effectiveness of Protected Areas: The United Kingdom”. Biol Conserv 132(1):76-87

Gibbons DW, Reid JB, Chapman RA (1993) The New Atlas of Breeding Birds in Britain and Ireland: 19881991. Poyser, London

Gilby BL, Olds AD, Brown CJ, Connolly RM, Henderson CJ, Maxwell PS, Schlacher TA (2021) “Applying Systematic Conservation Planning to Improve the Allocation of Restoration Actions at Multiple Spatial Scales". Restor Ecol 29(5). https://doi.org/10.1111/rec.13403

Gillingham PK, Alison J, Roy DB, Fox R, Thomas CD (2015) "High Abundances of Species in Protected Areas in Parts of Their Geographic Distributions Colonized during a Recent Period of Climatic Change". Conserv Lett 8(2):97-106

Gillings S, Balmer DE, Caffrey BJ, Downie IS, Gibbons DW, Lack PC, Reid JB, Sharrock JTR, Swann RL, Fuller RJ (2019) "Breeding and Wintering Bird Distributions in Britain and Ireland from Citizen Science Bird Atlases". Glob Ecol Biogeogr 28(7):866-874

Groves CR, Edward T, Game MG, Anderson M, Cross C, Enquist Z, Ferdaña E et al (2012) "Incorporating Climate Change into Systematic Conservation Planning”. Biodivers Conserv 21(7):1651-1671

Hannah L (2010) “A Global Conservation System for Climate-Change Adaptation”. Conserv Biol 24(1):70-77

Hiley JR, Bradbury RB, Holling M, Thomas CD (2013) "Protected Areas Act as Establishment Centres for Species Colonizing the UK”. Proc R Soc B: Biol Sci 280(1760): 20122310-20122310

Hill JK, Hannah M, Griffiths, Thomas CD (2011) "Climate Change and Evolutionary Adaptations at Species' Range Margins". Ann Rev Entomol 56(January):143-159

Hodgson JA, Chris D, Thomas BA, Wintle, Moilanen A (2009) "Climate Change, Connectivity and Conservation Decision Making: Back to Basics”. J Appl Ecol 46(5):964-969

Isaac NJB, Brotherton PNM, Bullock JM, Gregory RD, Boehning-Gaese K, Connor B, Crick HQP et al (2018) "Defining and Delivering Resilient Ecological Networks: Nature Conservation in England". J Appl Ecol 55(6):2537-2543

Johnston A, Ausden M, Dodd AM, Bradbury RB, Chamberlain DE, Jiguet F, Thomas CD et al (2013) "Observed and Predicted Effects of Climate Change on Species Abundance in Protected Areas". Nat Clim Change 3(November): 1055

Jones KR, Watson JEM, Possingham HP, Klein CJ (2016) "Incorporating Climate Change into Spatial Conservation Prioritisation: A Review". Biol Conserv 194:121-130

Joppa LN, Pfaff A (2009) "High and Far: Biases in the Location of Protected Areas". PLoS One 4(12):e8273

Knight AT, Driver A, Cowling RM, Maze K, Desmet PG, Lombard AT, Rouget M et al (2006) "Designing Systematic Conservation Assessments That Promote Effective Implementation: Best Practice from South Africa". Conserv Biol 20(3):739-750

Kremen C, Cameron A, Moilanen A, Phillips SJ, Thomas CD, Beentje H, Dransfield J et al (2008) "Aligning Conservation Priorities across Taxa in Madagascar with High-Resolution Planning Tools". Science 320(5873):222-226

Kujala H, Elith J, Moilanen A (2018) "Not All Data Are Equal: Influence of Data Type and Amount in Spatial Conservation Prioritisation.” Edited by Andres Lopez-Sepulcre. Methods Ecol Evol 9(11):2249-2261

Kujala H, Moilanen A, Gordon A (2018) "Spatial Characteristics of Species Distributions as Drivers in Conservation Prioritization.” Edited by Justin Travis. Methods Ecol Evol 9(4):1121-1132 
Kukkala AS, Moilanen A (2013) "Core Concepts of Spatial Prioritisation in Systematic Conservation Planning”. Biol Rev Camb Philos Soc 88(2):443-464

Kullberg P, Toivonen T, Pouzols FM, Lehtomäki J, Minin ED, Moilanen A (2015) "Complementarity and Area-Efficiency in the Prioritization of the Global Protected Area Network”. PLoS One 10(12):e0145231

Lawton JH, Brotherton PNM, Brown VK, Elphick C, Fitter AH, Forshaw J, Haddow RW et al (2010) "Making Space for Nature: A Review of England's Wildlife Sites and Ecological Network. Report to Defra". http://webarchive.nationalarchives.gov.uk/20130402151656/http://archive.defra.gov.uk/environment/ biodiversity/documents/201009space-for-nature.pdf

Lehtomäki J, Kusumoto B, Shiono T, Tanaka T, Kubota Y, Moilanen A (2018) "Spatial Conservation Prioritization for the East Asian Islands: A Balanced Representation of Multitaxon Biogeography in a Protected Area Network”. Divers Distrib 2(ddi.12869):18

Lennon JJ, Koleff P, Greenwood JJD, Gaston KJ (2003) “Contribution of Rarity and Commonness to Patterns of Species Richness". Ecol Lett 7(2):81-87

Maiorano L, Amori G, Montemaggiori A, Rondinini C, Santini L, Saura S, Boitani L (2015) "On How Much Biodiversity Is Covered in Europe by National Protected Areas and by the Natura 2000 Network: Insights from Terrestrial Vertebrates". Conserv Biol 29(4):986-995

Margules CR, Pressey RL (2000) "Systematic Conservation Planning”. Nature 405(6783):243-253

Mason SC, Palmer G, Fox R, Gillings S, Hill JK, Thomas CD, Oliver TH (2015) "Geographical Range Margins of Many Taxonomic Groups Continue to Shift Polewards”. Biol J Linn Soc 115(3):586-597

Maxwell SL, Cazalis V, Dudley N, Hoffmann M, Rodrigues ASL, Stolton S et al (2020) "Area-Based Conservation in the Twenty-First Century". Nature 586(7828):217-227

Moilanen A, Anderson BJ, Eigenbrod F, Heinemeyer A, Roy DB, Gillings S, Armsworth PR, Gaston KJ, Thomas CD (2011) "Balancing Alternative Land Uses in Conservation Prioritization". Ecol Appl 21(5):1419-1426

Moilanen A, Arponen A (2011) "Setting Conservation Targets under Budgetary Constraints". Biol Conserv 144(1):650-653

Moilanen A, Franco AMA, Early RI, Fox R, Wintle B, CD Thomas (2005) "Prioritizing Multiple-Use Landscapes for Conservation: Methods for Large Multi-Species Planning Problems". Proc Biol Sci 272(1575):1885-1891

Murphy JM, Sexton DMH, Jenkins GJ, Booth BBB, Brown CC, Clark RT, Collins M et al (2009) "UK Climate Projections Science Report:Climate Change Projections." Met Office Hadley Centre, Exeter

Oliver TH, Gillings S, Pearce-Higgins JW, Brereton T, Crick HQP, Duffield SJ, Morecroft MD, Roy DB (2017) "Large Extents of Intensive Land Use Limit Community Reorganization during Climate Warming” Glob Change Biol 23(6):2272-2283

Pearce-Higgins JW, Beale CM, Oliver TH, August TA, Carroll M, Massimino D, Ockendon N et al (2017) "A National-Scale Assessment of Climate Change Impacts on Species: Assessing the Balance of Risks and Opportunities for Multiple Taxa". Biol Conserv 213(Part A):124-134

Pierce SM, Cowling RM, Knight AT, Lombard AT, Rouget M, Wolf T (2005) "Systematic Conservation Planning Products for Land-Use Planning: Interpretation for Implementation”. Biol Conserv 125:441-458

Pocock MJO, Roy HE, Preston CD, Roy DB (2015) "The Biological Records Centre: A Pioneer of Citizen Science". Biol J Linn Soc 115(3):475-493

Pouzols FM, Toivonen T, Minin ED, Kukkala AS, Kullberg P, Kuusterä J, Lehtomäki J, Tenkanen H, Verburg PH, Moilanen A (2014) “Global Protected Area Expansion Is Compromised by Projected Land-Use and Parochialism”. Nature 516(7531):383-386

Prentice IA, Sykes MT, Cramer W (1993) “A Simulation Model for the Transient Effects of Climate Change on Forest Landscapes”. Ecol Model 65:51-70

Pressey RL, Bottrill CM (2008) "Opportunism, Threats, and the Evolution of Systematic Conservation Planning”. Conserv Biol 22(5):1340-1345

Preston CD, Pearman DA, Dines TD (2002) "New Atlas of the British and Irish Flora. An Atlas of the Vascular Plants of Britain. Ireland, the Isle of Man and the Channel Islands."

Pullin AS, Báldi A, Can OE, Dieterich M, Kati V, Livoreil B, Lövei B et al (2009) "Conservation focus on Europe: major conservation policy issues that need to be informed by conservation science." Conserv Biol 23(4):818-824

Ratcliffe DA (1984) "Post-Medieval and Recent Changes in British Vegetation: The Culmination of Human Influence". New Phytol 98(1):73-100

Ridding LE, Redhead JW, Pywell RF (2015) "Fate of Semi-Natural Grassland in England between 1960 and 2013: A Test of National Conservation Policy". Glob Ecol Conserv 4(July):516-525

Rogelj J, Meinshausen M, Knutti R (2012) "Global Warming under Old and New Scenarios Using IPCC Climate Sensitivity Range Estimates". Nat Clim Change 2(4):248-253

Saura S, Bodin Ö, Fortin MJ (2014) “Editor's choice: Stepping Stones Are Crucial for Species' Long-distance Dispersal and Range Expansion through Habitat Networks. ”J Appl Ecol. 
Shwartz A, Davies ZG, Macgregor NA, Crick HQP, Clarke D, Eigenbrod F, Gonner C et al (2017) "Scaling up from Protected Areas in England: The Value of Establishing Large Conservation Areas". Biol Conserv 212(Part A):279-287

Smith RJ, Peter S, Goodman, Matthews WS (2006) "Systematic Conservation Planning: A Review of Perceived Limitations and an Illustration of the Benefits, Using a Case Study from Maputaland, South Africa". Oryx 40(04):400

Starnes T, Beresford AE, Buchanan GM, Lewis M, Hughes A, Gregory RD (2021) "The Extent and Effectiveness of Protected Areas in the UK". Glob Ecol Conserv e01745

Stokstad E (2020) "Global Efforts to Protect Biodiversity Fall Short.” Science 369(6510):1418

Stralberg D, Carroll C, Nielsen SE (2020) "Toward a Climate-informed North American Protected Areas Network: Incorporating Climate-change Refugia and Corridors in Conservation Planning." Conserv Lett 13(4):e12712

Stroud DA, Chambers D, Cook S, Buxton N, Fraser B, Clement P, Lewis P, McLean I, Baker H, Whitehead S (2001) "The UK SPA Network:Its Scope and Content." JNCC 1-3

Suggitt AJ, Wilson RJ, Isaac NJB, Beale CM, Auffret AG, August T, Bennie JJ et al (2018) "Extinction Risk from Climate Change Is Reduced by Microclimatic Buffering." Nat Clim Change 8(8):713-717

Thomas CD, Barbara J, Anderson A, Moilanen F, Eigenbrod A, Heinemeyer T, Quaife DB, Roy S, Gillings PR, Armsworth, Gaston KJ (2013) "Reconciling Biodiversity and Carbon Conservation." Ecol Lett 16(1):39-47

Thomas CD, Gillingham PK (2015) “The Performance of Protected Areas for Biodiversity under Climate Change." Biol J Linn Soc 115(3):718-730

Thomas CD, Gillingham PK, Bradbury RB, Roy DB, Anderson BJ, Baxter JM, Bourn NAD et al (2012) "Protected Areas Facilitate Species’ Range Expansions.” Proc Natl Acad Sci USA 109(35):14063-14068

Venter O, Magrach A, Outram N, Klein CJ, Possingham HP, Marco MD, Watson JEM (2018) "Bias in Protected-Area Location and Its Effects on Long-Term Aspirations of Biodiversity Conventions: Protected Areas Missing Biodiversity." Conserv Biol 32(1):127-134

Wilson KA, Cabeza M, Klein CJ (2009) "Fundamental Concepts of Spatial Conservation Prioritization." In: Moilanen A, Wilson KA, Possingham H (eds) Spatial Conservation Prioritization: Quantitative Methods and Computational Tools. 16-27. Oxford, UK: Oxford University Press

Wilson KA, Underwood EC, Morrison SA, Klausmeyer KR, Murdoch WW, Reyers B, Wardell-Johnson $\mathrm{G}$ et al (2007) "Conserving Biodiversity Efficiently: What to Do, Where, and When." PLoS Biol 5(9):1850-1861

Publisher's note Springer Nature remains neutral with regard to jurisdictional claims in published maps and institutional affiliations.

\title{
Authors and Affiliations
}

\author{
Rob Critchlow ${ }^{1}$ Charles A. Cunningham ${ }^{1,2} \cdot$ Humphrey Q. P. Crick ${ }^{3}$. \\ Nicholas A. Macgregor ${ }^{3,4}$. Michael D. Morecroft ${ }^{3} \cdot$ James W. Pearce-Higgins $^{5} \cdot$ Tom $^{2}$ \\ H. Oliver ${ }^{6} \cdot$ Matthew J. Carroll $^{1}$. Colin M. Beale ${ }^{1,2}$
}

Rob Critchlow

rob.critchlow@york.ac.uk

Charles A. Cunningham

charles.cunningham@york.ac.uk

Humphrey Q. P. Crick

Humphrey.Crick@naturalengland.org.uk

Nicholas A. Macgregor

N.Macgregor@kent.ac.uk

Michael D. Morecroft

Mike.Morecroft@naturalengland.org.uk 
James W. Pearce-Higgins

james.pearce-higgins@bto.org

Tom H. Oliver

t.oliver@reading.ac.uk

Matthew J. Carroll

m.j.carroll.85@gmail.com

Colin M. Beale

colin.beale@york.ac.uk

1 Department of Biology, University of York, Wentworth Way, YO10 5DD York, UK

2 Leverhulme Centre for Anthropocene Biodiversity, Department of Biology, University of York, York YO10 5DD Heslington, UK

3 Natural England, Eastbrook, Shaftesbury Road, CB2 8DR Cambridge, UK

4 Durrell Institute of Conservation and Ecology (DICE), School of Anthropology and Conservation, University of Kent, CT2 7NR Canterbury, Kent, UK

5 BTO, The Nunnery, Thetford, Norfolk, UK

6 School of Biological Sciences, University of Reading, Whiteknights, PO Box 217, RG6 6AH Reading, Berkshire, UK 